\title{
OPEN ACCESS TO DIGITAL CULTURE FOR NON-PROFESSIONAL CREATIVES
}

\author{
Violetta Dajanev \\ Loughborough University School of Art and Design \\ Loughborough University \\ 9 Ball Street, NG3 3AX \\ Nottingham \\ United Kingdom \\ vd@ryotic.de \\ V.Dajanev@lboro.ac.uk \\ http://www.lboro.ac.uk/departments/ac/mainpages/postgraduate/research \\ $\% 20$ students/dajanev v.htm
}

\begin{abstract}
Technology enables those with access to ITC/Internet a range of opportunities to engage with the world through personal creative practice. However, many people found themselves excluded from the increasingly digitalizing modern society due to economic restraints and lack of new media literacy. This paper discusses whether Free and Open Source applications along with Creative Commons Licence are able to effect a social benefit by enabling non-professional creatives to participate in the culture of digital production.
\end{abstract}

\section{INTRODUCTION}

New developments in computer and communication technology over the last decade vastly changed our daily life. Digital technology and the Internet have become deeply embedded into different levels of modern society. "The ability to use a computer is assumed to be a cornerstone of effective citizenship in the Information Age" [1]. Today, not only the computer skills are essential but also a certain level of new media literacy is set as a social standard. A modern literate person is expected to be able to communicate online, to do research on the Internet, to modify and share data, to produce own content and make it available to others.

The tools of production that were once only in the hands of a few are now available to more people than ever before. With more than 1 billion camera phones produced in 2008 (ABI Research data), with affordable computers, digital video and photo cameras, an increased number of people are exploring the boundaries of, and expanding upon, the interactive capabilities of new technology, especially in relation to creative production and sharing. Manufacturers are competing in providing modern consumers with sophisticated new media tools for creative self-expression, content creation and active participation in digital culture.

Theoretically, digital technology and opportunities of production invite everybody to participate. However, the rapid technological progress causes a digital divide in the society. It is not an issue as being seen traditionally of 'having' or 'not having' the physical access to the technology and the Internet. With the increased availability of computer technology at homes, public places and institutions, it is important to look at 
not only who uses the computers and the Internet, but also to distinguish among people's varying levels of IT and online skills. Only a successful human-computer interaction can turn a human into a user and a new media creator. Some people, who are not able to operate computer technology and the Internet, find themselves excluded from the digital culture. Jenkins [2] emphasizes the importance of shifting from questions of technological access to those of opportunities to participate and to develop the cultural competencies and social skills needed for full involvement. The ability of online communication and networking has become essential in the modern world.

Participatory culture requires new literacies, which are "built on the foundation of traditional literacy, research skills, technical skills, and critical analysis skills" [3].

New Media Consortium offered in 2005 a definition of twenty-first century literacy, where it is described as the set of abilities and skills where aural, visual, and digital literacy overlap. These include the ability to understand the power of images and sounds, to recognize and use that power, to manipulate and transform digital media, to distribute them pervasively, and to easily adapt them to new forms [4].

This paper examines selected aspects of user participation in digital culture as well as obstacles that prevent some people from full involvement. We are looking at Free / Open Source Software and Creative Commons as a possible framework for nonprofessional creatives to engage with creative production and participate in social media networks. This could have a positive impact on media literacy level of those who apply the proposed tools for their digital creativity.

\section{THE CULTURE OF PARTICIPATION AND CONTENT CREATION}

Increased availability of digital technologies combined with the Internet allows almost everyone to become a media producer. If the early Internet was about consuming 'ready-made' information, Web 2.0 has an architecture specified for user participation and contribution. The websites that have policies aimed at the modern user's needs for self-expression and that have made it easy to share user-made content are the ones experiencing the fastest growth of popularity today. Portals like Wikipedia, Facebook, YouTube and Flickr, also described as social media represent modern networks of communication, exchange and media production.

6 out of the 10 top Internet sites are social (YouTube, live.com, Facebook, hi5, Wikipedia, Orkut); none were on the list in 2005 [5]. According to Alexa data, in April 2009, Wikipedia has ranked as number 7 most visited website; YouTube was at number 3, Facebook was at 4, and Blogger was at 8 [6].

The number of people participating in social networks and sharing their content is amazing. By 2009 Facebook has over 200 million active users and more than 1 billion pieces of content (stories, blog posts, notes, photos, etc.) shared each week [7].

We encounter an exponential growth of Wikipedia, the online encyclopaedia, based on the idea of Web 2.0 - the construct of collaborative knowledge. There are more than

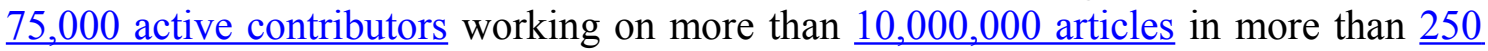
languages (by 2008). 
EVA 2009 London Conference 6-8 July

Violetta Dajanev

The whole structure of Web 2.0 offers various opportunities for individuals to engage with a variety of creative experiences, to try out for many a completely new role of a creator. Some people, especially the younger generation, are already actively involved in content production and sharing culture, which is often called 'participatory culture'. Jenkins [2] describes this phenomenon:

A participatory culture is a culture with relatively low barriers to artistic expression and civic engagement, strong support for creating and sharing one's creations, and some type of informal mentorship whereby what is known by the most experienced is passed along to novices. A participatory culture is also one in which members believe their contributions matter, and feel some degree of social connection with one another $[2]$.

The Pew Internet \& American Life project [8] reported in 2004 that 44\% of Internet users in the United States had created content for the Internet through building or posting to Web sites, creating blogs, and sharing files. According to a survey on bloggers in 2006, Pew Internet reports that the main reasons for keeping a blog are creative expression and sharing personal experiences. Unfortunately, such statistics could not be found for the UK. On this account, creativity is now seen as part of everyday life of 'ordinary' Internet users.

Trendwatching [9] reported in 2004 on a modern phenomenon of 'Generation C' where 'the $C$ stands for CONTENT, and anyone with even a tiny amount of creative talent can be a part of this not-so-exclusive trend'. Generation $\mathrm{C}$ fills the Internet with a mass of content, where the quality ranges from absolute amateur to almost professional level. Trendwatching distinguish two main drivers of this trend:

- The creative urges each consumer undeniably possesses. We're all artists, but until now we neither had the guts nor the means to go all out.

- The manufacturers of content-creating tools, who relentlessly push us to unleash that creativity, using -of course - their ever cheaper, ever more powerful gadgets and gizmos. Instead of asking consumers to watch, to listen, to play, to passively consume, the race is on to get them to create, to produce, and to participate [9].

However, some critics are sceptical about the impact computer technologies and the Internet have on our culture. Web 2.0 critic Andrew Keen [10] sees the Internet as a refuge for mediocrity and dilettantism. However, one of Keen's central arguments - that the Internet, by its all-inclusive nature and easy access, opens the door to amateurismas-authority while at the same time devaluing professional currency - seems unilateral. This is not a black-and-white issue. Leadbeater and Miller [11] view the current surge in non-professional creativity as a "new ethic of amateurism" that "could be one of the defining features of developed society". Their 'Pro-Ams' are a "new breed of amateurs who are knowledgeable, educated, skilled, no less committed than the professionals, but who do not derive their main income from these amateur activities". High-motivated, 
skilled and enthusiastic amateurs shape a bottom-up, self-organizing community that can achieve things that "until recently only large, professional organizations could achieve".A good example is 'Clickworkers' - an experiment run in 2000-2001 by NASA "to see if public volunteers, each working for a few minutes here and there can do some routine science analysis that would normally be done by a scientist or graduate student working for months on end". An analysis of the quality of markings showed "that the automatically computed consensus of a large number of clickworkers is virtually indistinguishable from the inputs of a geologist with years of experience". We support Benkler [12] who sees great practical promises in development of participatory culture. He points out its dimensions for individual freedom as well as its central role for the innovation economy and democracy.

\section{ACCESSIBILITY}

Technological evolution has brought to the wider public unprecedented opportunities to enjoy digital media and to participate in creation of new media popular culture. Although computer technology and the Internet have become widely accessible, why is only a part of society participating in digital life? Why do a significant part of Internet users remain passive consumers of data posted by others? Apart from a smaller group of people who consciously refuse using technology on the account of environmental, religious, philosophical and other personal beliefs, the majority is concerned that "the world, based on IT, is moving past them" [13].

According to the European Social Technographics report [14], 10\% of online adults in Europe are 'Creators'. 'Joiners' make up 13\% and are consumers who have taken the first real leap into interaction with social media by joining and participating in social networks such as Facebook or MySpace. Rather than just observing, these users have taken the next step into active engagement. 'Spectators' are the largest group. More than a third of online Europeans - 40\% - are 'Spectators', consumers who view and read social media content such as YouTube videos and forums but don't contribute. This is the largest single active segment, which suggests that many users start in just observing social technologies for a while before they begin to actively engage. Additionally, around half the online population - 53\% - is made up of 'Inactives', who don't engage with social technologies in any way. In the UK, $21 \%$ of the online population is made up of 'Joiners', compared with 13\% in Europe as a whole [14].

As we can derive from the figures above, the wide availability of computer technology and the Internet does not make it automatically accessible for everyone. Apart from the hardware, an operation system and at least a dozen of applications are required for a user to be able to produce and share data. However, any high-end multimedia computer can do nothing on its own; it requires a skilled user to operate it. A user must bring a basic understanding of how the system works, basic skills in using the software and how to search for and post data on the Internet.

A brand new computer rarely comes equipped with media production tools. It is often a hard decision for a home user on which software to use and where to find it. Manufacturers advertise their all-in-one easy-to-use tools that can turn an amateur into a professional. However, such programs are not cheap and hardly affordable for an 
'ordinary' user. Moreover, it is highly unlikely that anyone would spend a fortune for his or her non-profit creative efforts. Current copyright laws discourage people from exploiting their creative potential. Mass media spread fear of punishment for illegal use of commercial software, unauthorised use of multimedia data or distribution of creative content that is based on the works of others. The financial factor is a big barrier for many in accessing the technological opportunities of creative production.

As an answer to these limitations, alternative social movements are gaining in popularity, which share the main idea that the knowledge must be free. Free and Open Source movements (FLOSS), Creative Commons (CC) and Public Domain aim to spread freedom and cooperation, offering free resources and choice of copyright. L. Lessig's idea of Free Software Foundation can be applied to other areas of human creativity and allow everybody to take full advantage of the potential of digital technologies and computer networks.

\section{FREE / LIBRE / OPEN SOURCE SOFTWARE}

The Internet has allowed creativity to burgeon because many of its resources have been free. As Lessig [15] writes: "free resources have been crucial to innovation and creativity; without them, creativity is crippled" (p. 14). Richard Stallman, founder of the Free Software Foundation, famously reminded us to think of "free speech, not free beer" in order to understand the meaning of 'free' in case of Free Software. Lessig's definition is more pragmatic, and more useful: "a resource is 'free' if (1) one can use it without permission of anyone else; or (2) the permission one needs is granted neutrally" (p. 12).

The first software applications were free by default - free not only in the sense of 'zero cost', but also in the sense of 'freedom'. The users of the early computer technology, mostly engineers and scientists, were encouraged to improve the manufacturer-supplied software, and even to share their improvements with each other. Thus the era of easy and informal code sharing slowly faded away, and software became a source of proprietary value. People still did share, sometimes legally and sometimes not. But an important mental shift had taken place: unrestricted sharing was no longer the assumed default. One had to check first to make sure if it was allowed to share, or share covertly.

Free Software Foundation (FSF) of Cambridge, Massachusetts was founded in 1985 as a response to this overwhelming control and pressure. The foundation gave life to a project, GNU operating system, which might be accepted as "the backbone of the free programming community" [16]. As Stallman clarifies, GNU system is composed of free software developed by other people for their own purposes [17]. Today, GNU signifies the name of the campaign started for freedom. As Stallman noted, "If you want to accomplish something in the world, idealism is not enough you need to choose a method that works to achieve the goal. In other words, you need to be 'pragmatic', [18].

Richard Stallman sees Free Software as a moral issue. In fact, he emphasizes that freedom and community is more important than writing good code. For Stallman, as it 
is emphasized in the Free Software Definition, Free Software is "a matter of liberty, not price".

Because of the misinterpretation of 'free', free is often mistakenly understood and mixed up with free of charge. However, this is an important distinction one has to keep in mind when one talks about the consequences of free software for society in its ethical impact on it.

The lack of flexibility inherent in the Free Software Foundation's unforgiving ideological stance initiates alternative structure, which is known as 'Open Source Initiative'. Free Software Movement sees the software freedom as an ethical issue, Open Source, on the contrary, has a practical approach. It emphasizes the benefits of peer-to-peer development model serving the needs of end-users.

For the Open Source movement, non-free software is a suboptimal solution. For the Free Software movement, non-free software is a social problem and free software is the solution. (gnu.org).

Free / Libre / Open Source Software (FLOSS) can be used, copied, modified, shared, and redistributed with little or no restriction, allowing free access to its source code. The FLOSS tools are derivatives of software consumption. Proprietary software rarely fulfils user requirements and there is no chance to change anything within a program. The urge to exceed the limitations of proprietary software was one of the main reasons for emergence of Free Software Foundation and later Open Source. The concept of collaborative work based on user experience around the world enables the improvement of the tools and extension of their functionality continuously. Today, there are hundreds of FLOSS tools ranging from very simple and easy-to-use to professional that can compete with world leading companies like Adobe. For example, GIMP has almost reached Photoshop's functionality and has additional tools that Photoshop does not have. Nevertheless, this powerful image editor remains free and accessible to everyone. Similar examples could be found for almost any area of creative tools. Just to name few, Inkscape can be used instead of Illustrator, Scribus for InDesign.

The greatest obstacle blocking people from using FLOSS (Free Libre Open Source Software) is the lack of information on it. People in schools, universities and adult education classes are rarely introduced to the concept of Free and Open Source software and the tools themselves. FLOSS has a reputation as an underground movement that produces unreliable pieces of software with no documentation and support, which require advanced computer skills to operate them. However, several open source tools like Mozilla Firefox, Open Office, and various multimedia players have won increased popularity over the last few years. Famous open source web browser Mozilla Firefox 3.0 became the most popular web browser in Europe in March 2009, overtaking Microsoft Internet Explorer 7.0 for the first time, according to web analytics firm StatCounter [19].

Efforts such as the grassroots 'Spread Firefox' marketing group in 2004 seem to have been very effective at convincing people to try out the application. Once people try it, they appear to like it enough to continue using it. 


\section{FLOSS AND CREATIVE PRODUCTION}

Free and Open Source software has more to offer than just no-cost tools. It brings with it a culture of shared knowledge and building on the work of others for overall benefit. Everyone is free to create his or her own tools or modify the existing ones according to own needs. This gives the freedom to implement technically the most sophisticated artistic ideas.

Using FLOSS for digital creativity brings many benefits to its users. The most essential one is that a FLOSS user rarely remains isolated. Very quickly he or she becomes a part of a network consisting of communities, mailing lists, forums and portals that facilitate knowledge exchange and communication between the similarminded. A piece of software that brings one into a community is more useful than good software that has no more to offer than a HELP button. The power of FLOSS is in the vibrancy and strength of its communities, the pool of collaborative knowledge.

As a member of various communities and as an active participant of social media platforms, a user is more likely to enhance his or her knowledge and develop skills essential for cultural production.

If the early communities were aimed at FLOSS developers and codes, many websites today are narrowed to the needs of specific audiences like artists, musicians, and writers. Such projects as CREATE (http://create.freedesktop.org/) encourage communication and sharing between open source creative communities, joining them into a network of open creativity.

The resulting work of using FLOSS creativity support tools is often being published under Creative Commons (CC) copyleft licence where the author has the choice of copyright. Many works are completely free to use in any occasions. However, some of them are free only for non-profit projects. There is a growing number of online libraries of works published under CC like Open Clip Art Library (http://openclipart.org/) or Open Font Library (http://openfontlibrary.org/) that are aimed at collecting user contributed work that can be used freely and is accessible for everyone free of charge.

The increased familiarity with the FLOSS concept and its distinction from proprietary software can raise awareness of copyright and legal use among the broader public. This can help to reduce software piracy and encourage people to look for support in peer communities.

\section{CONCLUSION}

The concept of the Free Software and Open Source movements goes far beyond technological innovation only. The idea of openness and collaboration has political and cultural implications and is now frequently deployed in other areas of modern society. Reshaping the model of communication from top-down to peer-to-peer results in the commodification of the social processes involved in digital culture. The proclamations of openness and liberation of the right to produce lead to democratisation of media production. To name a few examples: 


\section{EVA 2009 London Conference 6-8 July \\ Violetta Dajanev}

- The Toronto-based website 5000Seconds announced a call for short submissions from people across the globe for an unusual online, user-generated feature film. The final film will be called 5000 Seconds : Our World, with the goal of creating a powerful snapshot of the world we live in.

- Xingtone.com lets consumers compose their own ringtones, and Sony PlayStation2's http://Noiseupthesuburbs.com invites an emerging generation of DIY music pioneers, from bedroom DJs and producers to pirate radio and independent label founders, to make use of its music-making software.

- The New York Times and BBC encourage citizen journalism, allowing users to post their stories, photographs and videos on web portals of these media giants.

As Gorunova [20] puts it, freedom also has a dimension of collectivity, collective experience, as it is linked into an understanding of a human being as a social and public being. Moreover, freedom is closely related to creativity.

Openness and creativity are essential for a modern democratic society. However, the excited supporters of new digital economy sometimes forget that the promoted technology often targets only a limited group of people with intermediate to advanced level of new media literacy. Those people know how to operate the system and have a basic set of software, as well as the Internet required for a full participation in digital culture.

With the regard of the importance of new media literacy in our digitalized society there is a need to think about ways of overcoming barriers that prevent a significant part of society from being media participants and contributors.

Thus, if the general public gets to know more about the powerful opportunities of Free and Open Source software as well as Web 2.0 and Creative Commons, it could encourage participation and development of new skills for digital inclusion.

\section{References}

[1] SELWYN, N. The social processes of learning to use computers. Social Science Computer Review. Vol. 23, No. 1, 2005. pp.122-135.

[2] JENKINS, H, et al. Confronting the challenges of participatory culture : media education for the $21^{\text {st }}$ century. Digital Media and Learning, MacArthur Foundation, 2006.

[3] JENKINS, H. Nine propositions towards a cultural theory of YouTube, 2007. http://www.henryjenkins.org/2007/05/9 propositions_towards_a_cultu.html [3.09.2008]

[4] NEW MEDIA CONSORTIUM. A global imperative : the report of the 21st century literacy summit. Austin, TX : New Media Consortium, 2005. http://www.nmc.org/pdf/Global Imperative.pdf [21.05.2008]

[5] SOCIAL MEDIA STATISTICS. http://socialmediastatistics.wikidot.com [5.04.2009]

[6] ALEXA. Top ranking websites. http://www.alexa.com/topsites [05.05.2009]

[7] FACEBOOK. Statistics. http://www.facebook.com/press/info.php?statistics [05.05.2009] 
EVA 2009 London Conference 6-8 July

Violetta Dajanev

[8] LENHART, A., HORRIGAN, J, and FALLOWS, D. Creation online, 2004. http://www.pewinternet.org/reports/pdfs/PIP Content_Creation_Report.pdf (1.06.08)

[9] TRENDWATCHING. Generation "C". Trendwatching, 2004. http://www.trendwatching.com/trends/GENERATION C.htm [03.04.2006]

[10] KEEN, A. The cult of the amateur. New York : Doubleday Currency, 2007.

[11] LEADBEATER, C. and MILLER, P. The Pro-Am revolution : how enthusiasts are changing our economy and society. Demos, 2004.

[12] BENKLER, Y. The wealth of networks : how social production transforms markets and freedom. New Haven and London : Yale University Press, 2006.

[13] CUSHMAN, M. and KLECUN, E. Non-users of computers in south London: their experiences and aspirations for use. (Penceil Paper 6). 2005.

http://penceil.lse.ac.uk/documents/06 WFIS.pdf

[14] EUROPEAN SOCIAL TECHNOGRAPHICS report, 2008. http://www.samsa.fr/wp-content/uploads/2008/08/social-technology-report.pdf [15.11.2008]

[15] LESSIG, L. The future of ideas : the fate of the commons in a connected world. New York : Random House, 2001. p.14.

[16] SÖDERBERG, J. Copyleft vs. copyright : a Marxist critique. First Monday, Vol. 7, No. 3, March 2002.

http://firstmonday.org/issues/issue7 3/soderberg/index.html [19.05.2007]

[17] STALLMAN, R. The GNU operating system and the free software movement. In : Chris DiBona, Sam Ockman and Mark Stone (editors), Open sources : voices from the open source revolution. O'Reilly Online Catalog, 1999.

[18] STALLMAN, R. Copyleft : pragmatic idealism, 2003. http://www.gnu.org/philosophy/pragmatic.html [15.04.2007]

[19] STATCOUNTER. Web analytic company. http://gs.statcounter.com [10.05.2009]

[20] GORUNOVA, O. Autocreativity : the operation of codes of freedom in art and culture. In : FLOSS + Art. edited by Aymeric Mansoux and Marloes de Valk.GOTO10, 2008. pp.92-117. 